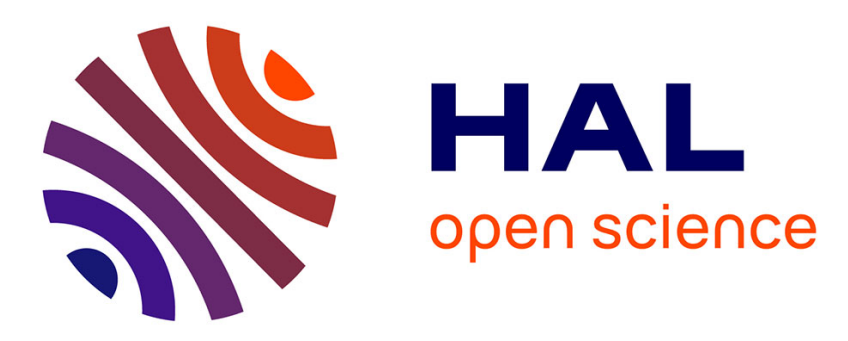

\title{
X-ray photoelectron spectroscopy analysis of Ge-Sb-Se pulsed laser deposited thin films
}

Emeline Baudet, Christophe Cardinaud, Remi Boidin, Aurelie Girard, Jan Gutwirth, Petr Nemec, Virginie Nazabal

\section{- To cite this version:}

Emeline Baudet, Christophe Cardinaud, Remi Boidin, Aurelie Girard, Jan Gutwirth, et al.. X-ray photoelectron spectroscopy analysis of Ge-Sb-Se pulsed laser deposited thin films. Journal of the American Ceramic Society, 2018, 101 (8), pp.3347-3356. 10.1111/jace.15512 . hal-01833232

HAL Id: hal-01833232

https://hal-univ-rennes1.archives-ouvertes.fr/hal-01833232

Submitted on 13 Jul 2018

HAL is a multi-disciplinary open access archive for the deposit and dissemination of scientific research documents, whether they are published or not. The documents may come from teaching and research institutions in France or abroad, or from public or private research centers.
L'archive ouverte pluridisciplinaire HAL, est destinée au dépôt et à la diffusion de documents scientifiques de niveau recherche, publiés ou non, émanant des établissements d'enseignement et de recherche français ou étrangers, des laboratoires publics ou privés. 
DR VIRGINIE NAZABAL (Orcid ID : 0000-0002-0113-3935)

Article type : Article

X-ray Photoelectron Spectroscopy analysis of Ge-Sb-Se pulsed laser deposited thin films

Emeline Baudet ${ }^{\ddagger}$, Christophe Cardinaud ${ }^{\S}$, Rémi Boidin ${ }^{\ddagger}$, Aurélie Girard ${ }^{\S}$, Jan Gutwirth ${ }^{\ddagger}$, Petr Němec ${ }^{\ddagger}$, Virginie Nazabal ${ }^{\mathbb{I}, \ddagger * *}$

Department of Graphic Arts and Photophysics, Faculty of Chemical Technology, University of Pardubice, Studentská 573, 53210 Pardubice, Czech Republic

§ Institut des Matériaux Jean Rouxel (IMN) UMR 6502, Université de Nantes, CNRS, 44322 Nantes Cedex 3, France

II Institut des Sciences Chimiques de Rennes, UMR-CNRS 6226, Equipe Verres et Céramiques, Université de Rennes 1, 35042 Rennes, France

*Author to whom correspondences should be addressed.

Email: virginie.nazabal@ univ-rennes1.fr

\section{Abstract}

Pulsed laser deposition was used to prepare amorphous thin films from $\left(\mathrm{GeSe}_{2}\right)_{100-\mathrm{x}}\left(\mathrm{Sb}_{2} \mathrm{Se}_{3}\right)_{\mathrm{x}}$ system $(\mathrm{x}=0,5,10,20,30,40,50$ and 60$)$. From a wide variety of chalcogenide glassforming systems, Ge-Sb-Se one, especially in thin films form, already proved to offer a great potential for photonic devices such as chemical sensors. This system has a large glassforming region which gives the possibility to adjust the chemical composition of the glasses 
according to required physical characteristics. The chemical composition of fabricated thin films was analyzed via X-ray photoelectron spectroscopy (XPS) and compared to energy dispersive spectroscopy (EDS) data. The results of both techniques agree well: a small deficiency in chalcogen element and an excess of antimony was found. The structure of asdeposited thin films has been investigated by XPS. The presence of the two main structural units, $\left[\mathrm{GeSe}_{4}\right]$ and $\left[\mathrm{SbSe}_{3}\right]$ proposed by Raman scattering spectroscopy data analysis, was confirmed by XPS. Moreover, XPS core level spectra analysis revealed the presence of M-M bonds $(\mathrm{M}=\mathrm{Ge}, \mathrm{Sb})$ in $(\mathrm{Ge}, \mathrm{Sb})-\mathrm{Ge}-(\mathrm{Se})_{3}$ and $(\mathrm{Ge}, \mathrm{Sb})-\mathrm{Sb}-(\mathrm{Se})_{2}$ entities that could correspond to Ge-based tetrahedra and Sb-based pyramids where one of its Se atoms at corners is substituted by $\mathrm{Ge}$ or $\mathrm{Sb}$ ones. The content of depicted $\mathrm{M}-\mathrm{M}$ bonds tends to increase with introduction of antimony in the amorphous network of as-deposited thin films from $\mathrm{x}=0$ to $\mathrm{x}=40$ and then it decreases. XPS analysis of as-deposited thin films shows also the presence of the $(\mathrm{Ge}, \mathrm{Sb})-\mathrm{Se}-(\mathrm{Ge}, \mathrm{Sb})$ and $\mathrm{Se}-\mathrm{Se}-(\mathrm{Ge}, \mathrm{Sb})$ entities.

\section{Introduction}

Chalcogenide glasses are amorphous materials based on $\mathrm{S}$, Se or Te element in combination with a suitable element from $13^{\text {th }}(\mathrm{Ga}, \mathrm{In}), 14^{\text {th }}(\mathrm{Si}, \mathrm{Ge})$ or $15^{\text {th }}(\mathrm{As}, \mathrm{Sb})$ group of the periodical table. They form an important class of inorganic materials studied many years for their specific properties leading to many interesting applications. Amorphous chalcogenides present unusual characteristics such as a wide transparency in the infrared range $(\approx 1-12 \mu \mathrm{m}$ for sulfides, $\approx 1-16 \mu \mathrm{m}$ for selenides and $\approx 2-20 \mu \mathrm{m}$ for tellurides) $)^{1,2}$, photosensitivity $^{3,4,5,6}$, high linear- and non-linear refractive index $7,8,9,10,11$ and a suitable shaping ability (to fabricate fibers ${ }^{12,13}$ or thin films ${ }^{14,15,16}$ ). Thereby various applications were developed using chalcogenide glasses: chemical and biochemical sensors ${ }^{17,18,19}$, components for high speed 
all-optical processing of telecommunications signals ${ }^{20,21}$ or phase change materials for rewritable data storage ${ }^{22}$.

Amorphous chalcogenides are commonly used as thin films, which can be fabricated from a solid material through different physical vapor deposition methods: RF magnetron sputtering $^{23,24,25}$, pulsed laser deposition (PLD) ${ }^{6,24,26}$, thermal evaporation ${ }^{23,26}$ or electron beam deposition ${ }^{27}$. Among mentioned methods, PLD seems to be promising for chalcogenide thin films fabrication due to its flexibility, easy control of the deposition process, possibility to fabricate multilayered structures and often stoichiometric material transfer from the target to the films $s^{5,6}$.

From a wide variety of chalcogenide glass-forming systems, $\mathrm{Ge}-\mathrm{Sb}-\mathrm{Se}$ one, especially in thin films form, already proved to offer a great potential for photonic devices such as chemical sensors $25,28,29$ because it does not contain arsenic, which is environmentally improper due to its high toxicity in elemental form ${ }^{23}$. This system has a large glass-forming region $^{30}$ which gives the possibility to adjust the chemical composition of the glasses according to required physical characteristics. The optical properties and structure of chalcogenide glasses within the pseudo-binary $\left(\mathrm{GeSe}_{2}\right)_{100-\mathrm{x}}\left(\mathrm{Sb}_{2} \mathrm{Se}_{3}\right)_{\mathrm{x}}(5 \leq \mathrm{x} \leq 70)$ system have previously been characterized ${ }^{7,31}$. Reported structural analyses of $\left(\mathrm{GeSe}_{2}\right)_{100-\mathrm{x}}\left(\mathrm{Sb}_{2} \mathrm{Se}_{3}\right)_{\mathrm{x}}$ glasses based on Raman scattering spectroscopy reveal a progressive change in the glassy network structure with the introduction of $\mathrm{Sb}_{2} \mathrm{Se}_{3}$ into $\mathrm{GeSe}_{2}$ amorphous matrix. In order to allow the insertion of $\left[\mathrm{SbSe}_{3 / 2}\right]$ entities, it is first favoring edge-shared [ $\left.\mathrm{GeSe}_{4 / 2}\right]$ entities to the detriment of $\left[\mathrm{GeSe}_{4 / 2}\right]$ tetrahedra linked by the corners. At intermediate $\mathrm{Sb}_{2} \mathrm{Se}_{3}$ content, glassy network contains significant number of $\left[\mathrm{SbSe}_{3 / 2}\right]$ trigonal pyramids. Finally, $\mathrm{Sb}_{2} \mathrm{Se}_{3}$ rich glasses seem to contain slightly higher number of homopolar $\mathrm{Sb}-\mathrm{Sb}, \mathrm{Ge}-\mathrm{Ge}$ and $\mathrm{Se}-\mathrm{Se}$ bonds ${ }^{7}$. When studying Raman spectra of corresponding thin films prepared by pulsed laser deposition in as-deposited state ${ }^{6}$, a higher proportion of homopolar Sb-Sb and $\mathrm{Ge}-\mathrm{Ge}$ bonds 
has been evidenced in comparison with parent bulk glasses. Consequently, in this paper we aim at studying the bonding arrangement at the surface of $\left(\mathrm{GeSe}_{2}\right)_{100-\mathrm{x}}\left(\mathrm{Sb}_{2} \mathrm{Se}_{3}\right)_{\mathrm{x}}(0 \leq \mathrm{x} \leq 60)$ as-deposited PLD thin films using X-ray photoelectron spectroscopy (XPS) to understand better PLD films's structural organization.

\section{Experimental Procedure}

Chalcogenide glasses with the $\left(\mathrm{GeSe}_{2}\right)_{100-\mathrm{x}}\left(\mathrm{Sb}_{2} \mathrm{Se}_{3}\right)_{\mathrm{x}}(0 \leq \mathrm{x} \leq 60)$ nominal composition were prepared using the conventional melting and quenching method ${ }^{7}$. Glasses were synthesized from high purity $(5 \mathrm{~N})$ commercial elements. Selenium was pre-purified by a static distillation. Elements were weighted in appropriate amounts and introduced in silica ampoules. The ampoules were then evacuated and sealed. The elements were melted in a rocking furnace at $800{ }^{\circ} \mathrm{C}$; ampoules with the melt were quenched in water and finally annealed at $20{ }^{\circ} \mathrm{C}$ below glass transition temperature $\left(\mathrm{T}_{\mathrm{g}}\right)$. Chalcogenide glasses with a diameter of $25 \mathrm{~mm}$ and a thickness of $3 \mathrm{~mm}$ used as PLD targets were obtained after slicing and polishing the glass rods.

Thin films were obtained by PLD. In detail, Ge-Sb-Se targets were ablated with a $\mathrm{KrF}$ excimer laser emitting at $248 \mathrm{~nm}$ (Compex 102, Lambda Physik) using $300 \pm 3 \mathrm{~mJ}$ output pulse energy, pulses duration of $30 \mathrm{~ns}$ and $20 \mathrm{~Hz}$ repetition rate. Laser fluency was set at 2.6 $\mathrm{J}_{\mathrm{cm}} \mathrm{c}^{-2}$. Background pressure in the vacuum chamber before deposition was about $3-4.10^{-4} \mathrm{~Pa}$. In order to obtain films with uniform thickness $( \pm 2 \%)$, off-axis PLD technique with rotating substrates and targets was used. Substrates were silicon wafers $(10 \times 15 \mathrm{~mm})$ which were positioned parallel to the target surface at a distance of $5 \mathrm{~cm}$. After the deposition, thin film samples around 0.7-1.2 $\mu \mathrm{m}$ were kept under vacuum $\left(5.10^{-5} \mathrm{mbars}\right)$, thus limiting any further surface contamination or chemical degradation (such as oxidation) until XPS surface analysis was carried out. The glass targets used for PLD originate from the glass-forming domain. The 
PLD process typically exhibits a cooling rate during the film growth much higher than conventional cooling for glass fabrication increasing the vitreous domain for the PLD films. However, to be sure about amorphous state of the films, XRD measurements for PLD films (in particular for $\mathrm{GeSe}_{2}$ and $\mathrm{Se} 7$ targets) were recorded with a D8-Advance diffractometer (Bruker AXS, Germany) with Bragg-Brentano $\theta-\theta$ geometry (40 kV, $40 \mathrm{~mA})$ using $\mathrm{CuK} \alpha$ radiation with secondary graphite monochromator. The XRD patterns were measured at room temperature from 5 to $65^{\circ}(2 \theta)$ within $0.02^{\circ}$ steps with a counting time of 5 s per step.

A Kratos Axis Ultra X-ray photoelectron spectrometer was employed to characterize the top surface of as-deposited Ge-Sb-Se thin films using monochromatic Al Ka X-rays (1486.6 eV, $15 \mathrm{kV}-15 \mathrm{~mA})$. Survey scans were recorded in the [+1250, $-5 \mathrm{eV}]$ binding energy (BE) range using the constant pass energy of $80 \mathrm{eV}$ and energy steps of $0.5 \mathrm{eV}$. High resolution spectra were further acquired within $\mathrm{Sb} 3 \mathrm{~d}-\mathrm{O}$ 1s, Se 3d, Sb 4d - Ge 3d core levels, using pass energy of $20 \mathrm{eV}$ and an energy step of $0.1 \mathrm{eV}$. The analysis was made at $0^{\circ}$ take off angle with respect to the normal to the sample surface. Data analysis of the core levels (Ge 2p $p_{3 / 2}, \mathrm{Sb} 3 \mathrm{~d}-\mathrm{O} 1 \mathrm{~s}$, Se 3d, Sb 4d - Ge 3d) was carried out with standard CASAXPS software ${ }^{32}$. Each $3 d(\mathrm{Ge}, \mathrm{Sb}, \mathrm{Se})$ and $4 \mathrm{~d}(\mathrm{Sb})$ core-level spectrum is constituted of $3 \mathrm{~d}_{5 / 2}$, $3 d_{3 / 2}$ and $4 d_{5 / 2}, 4 d_{3 / 2}$ spin orbits doublets. The binding energy scale has been calibrated on the Se $3 d_{5 / 2}$ peak of chalcogenide thin film with the nominal composition $\mathrm{Ge}_{28.1} \operatorname{Sb}_{6.3} \operatorname{Se}_{65.6}(\mathrm{x}=$ 10) positioned at $53.75 \mathrm{eV}$. Afterwards, other samples have been calibrated by aligning the Sb $3 \mathrm{~d}_{5 / 2}$ peak onto those obtained for previous sample (i.e. $528.85 \pm 0.08 \mathrm{eV}$ ). An "Offset Shirley" background was used for determining the spectral areas, in which the Linear to Shirley blend ratio was fixed to 1 . Line shapes for curve ftting were determined thanks to the analysis of a freshly fractured bulk glass $\mathrm{Ge}_{25} \mathrm{Sb}_{10} \mathrm{Se}_{65}$, whose structure presents almost only Ge-(Se) $)_{4}$ and $\mathrm{Sb}-(\mathrm{Se})_{3}$ environments. For the $\mathrm{Sb} 4 \mathrm{~d}$ and $\mathrm{Ge} 3 \mathrm{~d}$ spectra an Lorentzian Finite (LF) profile was used, in which the asymmetry parameters were set to unity to achieve a 
symmetric line shape; the tail damping and the width of the Gaussian were adjusted to the experimental spectrum, leading to $\operatorname{LF}(1,1,20,200)$ and $\operatorname{LF}(1,1,30,400)$ for the $\mathrm{Sb} 4 \mathrm{~d}$ and $\mathrm{Ge}$ 3d components respectively. For the Se3d spectrum a Gaussian-Lorentzian (GL(30)) profile was used. Concerning the fitting parameters, BE were free, Full Width at Half Maximum (FWHM) were free but constraint to be identical for all components of the same element, finally spin-orbit parameters (intensity ratio and $\mathrm{BE}$ separation) are fixed to $(0.667-0.57$ $\mathrm{eV}),(0.667-1.25 \mathrm{eV})$ and $(0.667-0.87 \mathrm{eV})$ for the Ge3d, Sb4d and Se3d spectrum respectively.

The chemical composition of $\left(\mathrm{GeSe}_{2}\right)_{100-\mathrm{x}}\left(\mathrm{Sb}_{2} \mathrm{Se}_{3}\right)_{\mathrm{x}}$ glassy targets and PLD thin films was measured using a scanning electron microscope with an energy-dispersive X-ray analyzer (EDS, JSM 6400-OXFORD Link INCA). A ZAF (effects of atomic number (Z), absorption within the sample and detector (A), and X-ray-induced fluorescence within the sample (F)) correction was used for the quantitative microanalysis. A $\mathrm{Ge}_{25} \mathrm{Sb}_{10} \mathrm{Se}_{65}$ commercial bulk glass was used to validate the quantification procedure for $\mathrm{Ge}-\mathrm{Sb}$-Se glass samples. Atomic percentage of each element $( \pm 0.5$ and $\pm 1 \%$ for the targets and the films, respectively) was extracted exploiting LLL lines of Ge, Sb and Se element working at $20 \mathrm{kV}$ for the targets and at $10 \mathrm{kV}$ for the films.

\section{Results and Discussion}

In order to compare the local structural units present in as-deposited $\left(\mathrm{GeSe}_{2}\right)_{100-\mathrm{x}}\left(\mathrm{Sb}_{2} \mathrm{Se}_{3}\right)_{\mathrm{x}}$ PLD thin films, XPS was used to describe bonding arrangement at the surface of the layers. Moreover, surface chemical composition was also studied by XPS and the obtained results were compared to EDS data. Fig. 1 shows an example of typical XPS survey spectrum of asdeposited thin film $\left(\mathrm{Ge}_{23.5} \mathrm{Sb}_{11.8} \mathrm{Se}_{64.7}\right.$, i.e. $\left.\mathrm{x}=20\right)$. The well-defined peaks are visible for $\mathrm{Ge}$, $\mathrm{Sb}$ and Se core level as well as Auger lines (Ge LMM, Sb MNN and Se LMM). No elements 
other than the thin films' components and residual oxygen were observed in all the $\left(\mathrm{GeSe}_{2}\right)_{100-\mathrm{x}}\left(\mathrm{Sb}_{2} \mathrm{Se}_{3}\right)_{\mathrm{x}}$ thin films' XPS survey spectra.

Table I presents the chemical composition data of the as-deposited thin films from $\left(\mathrm{GeSe}_{2}\right)_{100-\mathrm{x}}\left(\mathrm{Sb}_{2} \mathrm{Se}_{3}\right)_{\mathrm{x}}$ system determined by EDS in comparison with parent glass targets. Consequently, the chemical composition of PLD films was studied by XPS and compared to EDS values (Fig. 2). For all the Ge-Sb-Se compositions under study, the agreement between these two methods is fine and very similar general behavior is observed. Thereby, a deficiency in chalcogen content (lower than 4 at. \%) and an excess of antimony were observed in comparison with glass targets real composition. The loss of selenium is probably caused by its high volatility compared to germanium and antimony. In the case of germanium, when its content is lower than $\approx 25$ at. $\%$, the agreement between the composition of the films and theoretical one is very good as shown in Fig. 2. For higher Ge content, small excess of this element in the films is observed.

The bonding characteristics of as-deposited $\left(\mathrm{GeSe}_{2}\right)_{100-\mathrm{x}}\left(\mathrm{Sb}_{2} \mathrm{Se}_{3}\right)_{\mathrm{x}}(\mathrm{x}$ values varying from 0 to 60) thin films were studied by analyzing the core level XPS spectra taking into account earlier papers ${ }^{25,33,34}$. Fig. 3 (a, b, c) shows the $\mathrm{Sb} 4 \mathrm{~d}$ and Ge $3 \mathrm{~d}$ core level spectra for films with $x=5, x=20$ and $x=60$. The binding energy $(B E, e V)$, the full width at half maximum (FWHM, eV) and the proportion of bonds (\%) of the different components used for the fitting of core level spectra of as-deposited thin films are presented in Table II. As expected due to the chemical composition, the Sb core-level spectra area increases with the introduction of antimony (or increase of $\mathrm{x}$ value) and a corresponding decrease in the area of Ge core-level spectra is observed.

The Ge $3 \mathrm{~d}$ core-level spectra presents a primary component at $\approx 30.30 \mathrm{eV}( \pm 0.05 \mathrm{eV})$. Additional doublets have to be introduced to correctly fit the Ge 3d core-level spectra, one with lower BE value (from 29.57 to $30.04 \mathrm{eV}$ ) and one with higher BE value (from 31.40 to 
$31.64 \mathrm{eV}$ ). The different $\mathrm{BE}$ of each structural units is determined by the neighboring atom electronegativity. Accordingly, the binding energy downshift will be larger when the difference of neighboring atom electronegativity is larger. From the electronegativities of Ge, $\mathrm{Sb}$ and $\mathrm{Se}(2.01,2.05$ and 2.55 respectively in view of Pauling scale), the chemical environments can be deduced. The primary component at $\approx 30.30 \mathrm{eV}$ is assigned to the regular Ge-(Se) $)_{4}$ environment corresponding to $\left[\mathrm{GeSe}_{4 / 2}\right]$ tetrahedra. The doublet observed at lower BE (from 29.57 to $30.04 \mathrm{eV}$ ) should be attributed to the (Ge,Sb)-Ge-(Se) ${ }_{3}$ environment i.e. to a distorted tetrahedra where one Se atom is substituted with $\mathrm{Ge}$ or $\mathrm{Sb}$ atom (because of their very similar electronegativities) forming M-M bonds. Finally, the doublet at higher BE value (from 31.40 to $31.64 \mathrm{eV}$ ) is attributed to the oxide $\left(\mathrm{Se}_{\mathrm{y}}\right)-\mathbf{G e}-\mathrm{O}_{\mathrm{x}}$ because of the high electronegativity of $\mathrm{O}(3.44)^{25}$.

In analogy, three doublets are used to describe the $\mathrm{Sb} 4 \mathrm{~d}$ core-level spectra. The primary component is located from 32.66 to $32.78 \mathrm{eV}$ and is attributed to the regular $\mathrm{Sb}-(\mathrm{Se})_{3}$ arrangement of $\left[\mathrm{SbSe}_{3 / 2}\right]$ trigonal pyramid. $\mathrm{M}-\mathrm{M}$ bonds are also observed with the second doublet located at lower BE (from 32.23 to $32.65 \mathrm{eV}$ ) and attributed to $(\mathrm{Ge}, \mathrm{Sb})-\mathrm{Sb}-(\mathrm{Se})_{2}$ environment. As in the case of Ge $3 \mathrm{~d}$ core-level spectra, a third doublet is used to correctly fit the $\mathrm{Sb} 4 \mathrm{~d}$ core-level spectra of as-deposited thin films and it is attributed to $\left(\mathrm{Se}_{\mathrm{y}}\right)-\mathrm{Sb}-\mathrm{Ox}$ (at $34.02 \mathrm{eV})^{25,}{ }^{34}$. However, $\left(\mathrm{Se}_{\mathrm{y}}\right)-\mathrm{Sb}-\mathrm{Ox}$ is clearly observed for only $\left(\mathrm{GeSe}_{2}\right)_{70}\left(\mathrm{Sb}_{2} \mathrm{Se}_{3}\right)_{30}$ asdeposited thin film (Table II).

Fig. 4a shows normalized core level band of $\mathrm{Sb} 4 \mathrm{~d}-\mathrm{Ge} 3 \mathrm{~d}$ for $\left(\mathrm{GeSe}_{2}\right)_{100-\mathrm{x}}\left(\mathrm{Sb}_{2} \mathrm{Se}_{3}\right)_{\mathrm{x}}$ thin films, dashed lines correspond to the binding energies associated to the different entities considered of $x=10$ sample which was used for the calibration. A slight shift towards higher energies can be observed with the introduction of antimony. In detail, in Ge $3 \mathrm{~d}$ core level spectra, the doublet attributed to $(\mathrm{Ge}, \mathrm{Sb})-\mathbf{G e}-(\mathrm{Se})_{3}$ binding arrangement is shifted from 29.57 $\mathrm{eV}(\mathrm{x}=5)$ to $29.99 \mathrm{eV}(\mathrm{x}=60)$. Likewise the doublet in the $\mathrm{Sb} 4 \mathrm{~d}$ core level spectra, which is 
attributed to $(\mathrm{Ge}, \mathrm{Sb})-\mathrm{Sb}-(\mathrm{Se})_{2}$ binding arrangement, is shifted from $32.23 \mathrm{eV}(\mathrm{x}=5)$ to 32.65 $\mathrm{eV}(\mathrm{x}=60)$.

The presence of $\mathrm{M}-\mathrm{M}$ bonds $(\mathrm{M}=\mathrm{Ge}, \mathrm{Sb})$ was also demonstrated for bulk $\mathrm{Ge}-\mathrm{Sb}-\mathrm{Se}$ glasses $^{7,31,34}$ and thin films ${ }^{6,23,33}$. Sati et al ${ }^{34}$ used an additional doublet to fit $\mathrm{Sb} 4 \mathrm{~d}$ core level (at $\approx 32.20 \pm 0.05 \mathrm{eV}$ ) which was attributed to a distorted Sb-based trigonal pyramid with substitution of two and more Se atoms by Ge or $\mathrm{Sb}$ atoms ${ }^{34}$. Further, an additional doublet was used to fit the Ge $3 \mathrm{~d}$ core level spectra at $\approx 29.90 \pm 0.05 \mathrm{eV}$ in $\mathrm{Ge}_{28} \mathrm{Sb}_{12} \mathrm{Se}_{60}$ and $\mathrm{Ge}_{32} \mathrm{Sb}_{8} \mathrm{Se}_{60}$ glasses; this doublet was assigned to $(\mathrm{Ge}, \mathrm{Sb})_{2}-\mathrm{Ge}-(\mathrm{Se})_{2}$ bonding arrangement ${ }^{34}$. In contrast with this XPS analysis of Ge-rich $\mathrm{Sb}_{\mathrm{x}} \mathrm{Ge}_{40-\mathrm{x}} \mathrm{Se}_{60}$ glasses ${ }^{34}$, the mentioned additional doublet associated to $\mathrm{Sb}$ and Ge entities with a substitution of two and more $\mathrm{Se}$ atoms by $\mathrm{Ge}$ or $\mathrm{Sb}$ atoms were not required for the description of $\mathrm{Sb} 4 \mathrm{~d}-\mathrm{Ge} 3 \mathrm{~d}$ core level spectra in this work.

As results from XPS data analysis performed in this study, the proportion of $\mathrm{Sb}-(\mathrm{Se})_{3}$ arrangements increases from 3.9 at.\% (for $\mathrm{x}=5$ ) to 28.4 at.\% (for $\mathrm{x}=60$ ) and the proportion of $\mathrm{Ge}-(\mathrm{Se})_{4}$ arrangements decreases from 33.1 at.\% (for $\mathrm{x}=0$ ) to 7.9 at.\% (for $\mathrm{x}=60$ ) (Table 2). These values confirm that the amorphous network of as-deposited thin films slowly evolves from a $\left[\mathrm{GeSe}_{4 / 2}\right]$ tetrahedra dominated structure to a $\left[\mathrm{SbSe}_{3 / 2}\right]$ trigonal pyramidal one. Furthermore, the proportion of $(\mathrm{Ge}, \mathrm{Sb})-\mathrm{Sb}-(\mathrm{Se})_{2}$ bonds ranges from 6.5 to $21 \%$ (from $\mathrm{x}=5$ to 20) and then this proportion decreases to $7.5 \%(x=60)$ (Table II). Similarly, the proportion of $(\mathrm{Ge}, \mathrm{Sb})-\mathrm{Ge}-(\mathrm{Se})_{3}$ bonds increases from 10.3 to $29.5 \%$ from $\mathrm{x}=0$ to 50 and then decreases to $16.6 \%$ for $\mathrm{x}=60$ (Table II). The lower value observed for $\mathrm{x}=30$ film could be related to more important amount of $\left(\mathrm{Se}_{\mathrm{y}}\right)-\mathbf{S b}-\mathrm{O}_{\mathrm{x}}(11.7 \%)$ and $\left(\mathrm{Se}_{\mathrm{y}}\right)-\mathbf{G e}-\mathrm{O}_{\mathrm{x}}(5.8 \%)$ bonds at the surface of the films. Fig. 5 presents the M-M bonds proportions (at. \%) i.e. $\mathrm{Ge}-\mathrm{Ge}, \mathrm{Sb}-\mathrm{Sb}$ and $\mathrm{Ge}-\mathrm{Sb}$ bonds observed in Ge3d and Sb4d core level spectra. Introduction of antimony in thin films' network leads to M-M bonds increase first due to $(\mathrm{Ge}, \mathrm{Sb})-\mathbf{G e}-(\mathrm{Se})_{3}$ and then to $(\mathrm{Ge}, \mathrm{Sb})-\mathbf{S b}$ - 
$(\mathrm{Se})_{2}$. The decrease of M-M bonds observed for $\mathrm{x}>30$ can be explained by the glass network character which evolves to a network dominated by [ $\left.\mathrm{SbSe}_{3}\right]$ pyramids (Table 2). Raman analysis of PLD as-deposited thin film is somewhat different ${ }^{6}$. In fact, a decrease of Ge-Ge bonds (at $\approx 170$ and $\approx 270 \mathrm{~cm}^{-1}$ ) is observed with the introduction of antimony in thin films network. Furthermore, proportion of Sb-Sb bonds (at $\approx 155 \mathrm{~cm}^{-1}$ ) seems to slightly increase with $\mathrm{x}$ values and Raman spectra are dominated by $\mathrm{Sb}-\mathrm{Se}\left(\approx 190 \mathrm{~cm}^{-1}\right)$ bonds for as-deposited thin films with $\mathrm{x}>50$.

In the case of XPS analysis of selenium, two doublets $\left(3 d_{5 / 2}\right.$ and $\left.3 d_{3 / 2}\right)$ were used to fit correctly Se 3d core level spectra. Fig. 3 (d, e and f) illustrates fitting of Se 3d core level spectra for $x=5,20$ and 60 . The Se $3 d$ core level spectra presents a main component located from 53.47 to $53.78 \mathrm{eV}$ depending on composition which can be attributed to the (Ge,Sb)-Se$(\mathrm{Ge}, \mathrm{Sb}$ ) entities (Table 2). The second doublet, located from 54.02 to $54.35 \mathrm{eV}$, is assigned to the Se-Se-(Ge,Sb) entities ${ }^{33,34,35}$. A very slight shift towards lower energies was observed for PLD films with the introduction of antimony as shown in Fig. 4b. Therefore Se-Se-(Ge,Sb) and $\mathrm{Se}-(\mathrm{Ge}, \mathrm{Sb})_{2}$ arrangements are shifted from 54.35 to $54.02 \mathrm{eV}$ (from $\mathrm{x}=0$ to $\mathrm{x}=40$ ) and from 53.75 to $53.47 \mathrm{eV}$ (from $\mathrm{x}=5$ to $\mathrm{x}=40$ ) (Table 2). The content of $(\mathrm{Ge}, \mathrm{Sb})-\mathrm{Se}-(\mathrm{Ge}, \mathrm{Sb})$ $(80.8-89.9 \%)$ and Se-Se-(Ge,Sb) $(10.1$ - $19.2 \%)$ bonds is almost independent of composition for all $\left(\mathrm{GeSe}_{2}\right)_{100-\mathrm{x}}\left(\mathrm{Sb}_{2} \mathrm{Se}_{3}\right)_{\mathrm{x}}$ thin films (Table 2). Due to the comparable electronegativities of $\mathrm{Ge}$ and $\mathrm{Sb}$, the contributions from $\mathrm{Ge}$ and $\mathrm{Sb}$ are similar but not exactly the same. Indeed, Sati et al. ${ }^{34}$ reported higher FWHM values for the two doublets attributed to $(\mathrm{Ge}, \mathrm{Sb})-\mathrm{Se}-(\mathrm{Ge}, \mathrm{Sb})$ and $\mathrm{Se}-\mathrm{Se}-(\mathrm{Ge}, \mathrm{Sb})$ environments $(0.8-0.9 \mathrm{eV})$ in comparison to doublets of binary Ge-Se chalcogenide glasses $(0.6-0.7 \mathrm{eV})$. In the case of Ge-Sb-Se sputtered thin films, FWHM values of those doublets are also higher $(0.9-1.0 \mathrm{eV})^{33}$. In the line with mentioned data, XPS bands of as-deposited PLD thin films present also higher FWHM values (0.8-1.0 eV, Table 2), similar to Ge-Sb-Se bulk glasses and sputtered thin films. 
Our previous XPS analysis ${ }^{33}$ performed with RF sputtered thin films with the nominal composition $\mathrm{Ge}_{28.1} \mathrm{Sb}_{6.3} \mathrm{Se}_{65.6}(\mathrm{x}=10)$ presents comparable proportion of $\mathrm{M}-\mathrm{M}$ bonds as follows. Considering the closest chemical composition of as-deposited PLD thin films (i.e. comparison with the films sputtered at Ar pressure of $\left.1.10^{-2} \mathrm{mbar}\right)$, the proportion of (Ge,Sb)Ge-(Se) $)_{3}$ entities is about $14.1 \%$ (Table 2 ) and $12 \%$ for as-deposited PLD and sputtered thin films, respectively. In the same way, the proportion of $(\mathrm{Ge}, \mathrm{Sb})-\mathrm{Sb}-(\mathrm{Se})_{2}$ entities is about $11.5 \%$ (Table 2) and 9\% for PLD and sputtered thin films, respectively. As mentioned above, local structure analysis of $\left(\mathrm{GeSe}_{2}\right)_{100-\mathrm{x}}\left(\mathrm{Sb}_{2} \mathrm{Se}_{3}\right)_{\mathrm{x}}$ bulk glasses ${ }^{7}, \mathrm{PLD}^{6}$ and sputtered thin films ${ }^{33}$ (for $\mathrm{x}=10$ and $\mathrm{x}=50$ ) using Raman spectroscopy has been previously reported. The presence of homopolar Ge-Ge bonds in $\mathrm{Ge}_{2} \mathrm{Se}_{6 / 2}$ and $\mathrm{Ge}_{-} \mathrm{Ge}_{\mathrm{m}} \mathrm{Se}_{4-\mathrm{m}}(\mathrm{m}=1,2,3,4)$ species and $\mathrm{Sb}$ $\mathrm{Sb}(\mathrm{Ge})$ bonds of $\mathrm{Se}_{2} \mathrm{Sb}-\mathrm{Sb}(\mathrm{Ge}) \mathrm{Se}_{2(3)}$ structural units in PLD films was confirmed by Raman spectroscopy.

On the other hand, M-M bonds proportion seems to be to some extent overestimated by XPS analysis for as-deposited PLD thin films with the nominal composition $\mathrm{Ge}_{12.5} \mathrm{Sb}_{25} \mathrm{Se}_{62.5}(\mathrm{x}=50)$. In fact, the proportion of $(\mathrm{Ge}, \mathrm{Sb})-\mathrm{Ge}-(\mathrm{Se})_{3}$ entities is about $29.5 \%$ (Table II) and 7\% for as-deposited PLD and sputtered thin films, respectively. Further, the proportion of $(\mathrm{Ge}, \mathrm{Sb})-\mathbf{S b}-(\mathrm{Se})_{2}$ entities is about $15.0 \%$ (Table II) and 0\% for PLD and sputtered thin films, respectively. This is consistent with Raman analysis of sputtered thin films ${ }^{33}$ which demonstrates that for higher Ar pressure, the M-M bonds are almost not observed. If we consider the Raman spectroscopy data for sputtered film deposited with $\mathrm{Ar}$ pressure lower than $1.10^{-2}$ mbar, the spectrum of PLD film ( $\left.x=50\right)$ looks like Raman spectra of such sputtered films. The PLD film Raman spectrum shape is between those of two sputtered films (7.5.10 ${ }^{-3}$ and $5.10^{-3}$ mbar). From XPS analysis, the proportion of $(\mathrm{Ge}, \mathrm{Sb})-\mathrm{Ge}-$ $(\mathrm{Se})_{3}$ entities for these two sputtered films is $19 \%$ and $47 \%$, respectively. The semiquantitative analysis of Raman spectra of PLD film ( $x=50)$ compared to sputtered films let 
expect proportion of $(\mathrm{Ge}, \mathrm{Sb})-\mathbf{G e}-(\mathrm{Se})_{3}$ entities around $22-25 \%$. Thus, the general agreement between Raman and XPS analysis is good keeping in mind that only first ten nanometers are probed by XPS. Although, it seems that there is a slight overestimation of $(\mathrm{Ge}, \mathrm{Sb})-\mathrm{Ge}-(\mathrm{Se})_{3}$ entities by the XPS analysis of PLD film $(x=50)$.

The BE values found for PLD layers are in good agreement with sputtered thin films' XPS analysis: Ge-(Se) $)_{4}$ and $\mathbf{S b}-(\mathrm{Se})_{3}$ entities are located at 30.29 and $32.71 \mathrm{eV}$ and 30.37 and $32.73 \mathrm{eV}$ for as-deposited PLD and sputtered thin films with the nominal composition $\mathrm{Ge}_{28.1} \mathrm{Sb}_{6.3} \mathrm{Se}_{65.6}(\mathrm{x}=10)$. For Sb-rich thin films, mentioned two main entities are located at 30.32 and $32.78 \mathrm{eV}$ and 30.34 and $32.71 \mathrm{eV}$ for as-deposited PLD and sputtered thin films, again in very good agreement.

Likewise, Se-Se homonuclear bonds were also revealed in Raman and XPS analysis of RF sputtered thin films with the nominal chemical composition $\mathrm{Ge}_{28.1} \operatorname{Sb}_{6.3} \mathrm{Se}_{65.6}(\mathrm{x}=10)$ and $\mathrm{Ge}_{12.5} \mathrm{Sb}_{25} \mathrm{Se}_{62.5}(\mathrm{x}=50)^{33}$. The comparison of PLD and sputtered layers with $\mathrm{x}=10$ gives the proportion of Se-Se-(Ge,Sb) entities about $13.6 \%$ (Table 2) and 14\% for as-deposited PLD and sputtered thin films (at $1.10^{-2}$ mbar Ar) ${ }^{33}$, respectively. In layers with $x=50$, the content of Se-Se-(Ge,Sb) entities is about $16.2 \%$ (Table 2) and 22\% for as-deposited PLD and sputtered (at $1.10^{-2}$ mbar) thin films, respectively. Binding energies revealed for PLD thin films are also in agreement with those observed for RF sputtered thin films. For $x=10$ films, Se-Se-(Ge,Sb) entities are located at $54.30 \mathrm{eV}$ (Table 2) and $54.32 \mathrm{eV}$ for as-deposited PLD and sputtered $\left(1.10^{-2}\right.$ mbar Ar pressure) layers, respectively ${ }^{33}$. For Sb-rich thin films $(x=50)$, these entities are situated at $54.06 \mathrm{eV}$ (Table 2) and $54.10 \mathrm{eV}$ for PLD and sputtered $\left(1.10^{-2}\right.$ mbar Ar pressure) layers, respectively ${ }^{33}$. Raman data analysis of RF sputtered thin films also revealed the presence of Se-Se bonds, especially for higher Ar pressure, with the amplitude increase of the band located at $\approx 265 \mathrm{~cm}^{-1} 33$. These results also agree with previous XPS data obtained for RF sputtered thin film with the nominal composition $\mathrm{Ge}_{25} \mathrm{Sb}_{10} \mathrm{Se}_{65}$; the 
proportion of Se-Se-(Ge,Sb) is about $13 \%$ (for $5.10^{-3} \mathrm{mbar}$ ) and $29 \%$ (for $5.10^{-2} \mathrm{mbar}{ }^{25}$. The proportion of Se-Se homonuclear bonds is surprisingly high in these both compositions $(x=10$ and $\mathrm{x}=50$ ) close to stoichiometric composition or with deficit in chalcogen element as shown in Table I with relatively low content of M-M bonds. As it was already mentioned in previous work $^{25,33}$, another contribution to this second Se $3 \mathrm{~d}$ core level component spectrum might be considered: Se involved in bonds between two $\left[\mathrm{GeSe}_{4 / 2}\right]$ tetrahedra connected by edges could also contribute to $\mathrm{Se}-\mathrm{Se}-(\mathrm{Ge}, \mathrm{Sb})$ component.

It is worthy to mention that other techniques were already used for the structural analysis of Ge-Sb-Se glasses, for example neutron diffraction, X-ray diffraction or extended X-ray fine structure analysis. Pethes et al. ${ }^{36}$ used the reverse Monte-Carlo simulation technique ${ }^{37}$ to investigate $\mathrm{Ge}_{20} \mathrm{Sb}_{5} \mathrm{Se}_{75}, \mathrm{Ge}_{20} \mathrm{Sb}_{15} \mathrm{Se}_{65}$ and $\mathrm{Ge}_{20} \mathrm{Sb}_{20} \mathrm{Se}_{60}$ glasses. All three glass compositions show a structure mostly described by the chemically ordered network model in which Ge-Se and Sb-Se bonds are preferred. For calculations using the reverse Monte Carlo method, homopolar Se-Se bonds in Se-poor glass and M-M bonds in Se-rich glass are not needed which is distinctive to the analysis performed by XPS spectroscopy for physical vapor deposited Ge-Sb-Se films. However, the rapid quenching during the synthesis of the thin films is likely to generate more defects than parent glasses and deviate from a perfect chemically ordered network model.

\section{Conclusion}

In this paper, amorphous chalcogenide thin films with the nominal composition $\left(\mathrm{GeSe}_{2}\right)_{100-}$ ${ }_{x}\left(\mathrm{Sb}_{2} \mathrm{Se}_{3}\right)_{\mathrm{x}}(\mathrm{x}=0,5,10,20,30,40,50$ and 60) were deposited by PLD with chemical composition relatively close to the targets' composition. Nevertheless, EDX and XPS analysis, performed on glass targets and as-deposited thin films, reveals a small deficit in 
chalcogen element (Se) and an excess of Sb in the PLD films. The as-deposited thin films were characterized by X-rays photoelectron spectroscopy in order to describe bonding arrangement at the surface films. XPS investigations confirm the presence of the two main regular units $\mathbf{G e}-(\mathrm{Se})_{4}$ and $\mathbf{S b}-(\mathrm{Se})_{3}$. The $\mathrm{Sb}$ core level spectra amplitude increases logically with introduction of antimony so the amorphous network of as-deposited thin films slowly evolves from a $\left[\mathrm{GeSe}_{4 / 2}\right]$ tetrahedra dominated structure to a $\left[\mathrm{SbSe}_{3 / 2}\right]$ pyramidal one. The $(\mathrm{Ge}, \mathrm{Sb})-\mathbf{G e}-(\mathrm{Se})_{3}$ and $(\mathrm{Ge}, \mathrm{Sb})-\mathrm{Sb}-(\mathrm{Se})_{2}$ environments, corresponding to distorted tetrahedra or trigonal pyramid where one chalcogen element is substituted with $\mathrm{Ge}$ or $\mathrm{Sb}$ atom(s) forming M-M bonds, were also observed. The proportion of M-M bonds increases with the introduction of antimony (from $\mathrm{x}=0$ to $\mathrm{x}=40$ ) first due to $(\mathrm{Ge}, \mathrm{Sb})-\mathrm{Ge}-(\mathrm{Se})_{3}$ and then thanks to $(\mathrm{Ge}, \mathrm{Sb})-\mathrm{Sb}-(\mathrm{Se})_{2}$ entities' appearance. The study of Se 3d core level spectra reveals the presence of two entities: (Ge,Sb)-Se-(Ge,Sb) and Se-Se-(Ge,Sb). XPS analysis of asdeposited thin films seems to overestimate Se-Se homonuclear bonds, thus this component could contain also Se involved in two $\left[\mathrm{GeSe}_{4 / 2}\right]$ tetrahedra connected by edges.

\section{Acknowledgments}

This work was financially supported by the Czech Science Foundation (Project No. 1617921S). This work was also supported by the grants LM2015082, CZ.1.05/4.1.00/11.0251 and Barrande 7AMB17FR058 project from the Czech Ministry of Education, Youth and Sports of the Czech Republic and PHC-Barrande (2017-2018) from French Ministery of Education and Research. 


\section{References}

1. Zhang, X. H., Bureau, B., Lucas, P., et al., "Glasses for seeing beyond visible," Chemistry-a European Journal, 14[2] 432-42 (2008).

2. Vigreux-Bercovici, C., Ranieri, V., Labadie, L., et al., "Waveguides based on Te2As3Se5 thick films for spatial interferometry," J. Non-Cryst. Solids, 352[23-25] 2416-19 (2006).

3. Meneghini, C. and Villeneuve, A., "As2S3 photosensitivity by two-photon absorption: holographic gratings and self-written channel waveguides," Journal of the Optical Society of America BOptical Physics, 15[12] 2946-50 (1998).

4. Shimakawa, K., Kolobov, A., and Elliott, S. R., "Photoinduced effects and metastability in amorphous semiconductors and insulators," Advances in Physics, 44[6] 475-588 (1995).

5. Nemec, P., Zhang, S., Nazabal, V., et al., "Photo-stability of pulsed laser deposited GexAsySe100x-y amorphous thin films," Opt. Express, 18[22] 22944-57 (2010).

6. Olivier, M., Nemec, P., Boudebs, G., et al., "Photosensitivity of pulsed laser deposited Ge-Sb-Se thin films," Optical Materials Express, 5[4] 781-93 (2015).

7. Olivier, M., Tchahame, J. C., Nemec, P., et al., "Structure, nonlinear properties, and photosensitivity of $(\mathrm{GeSe} 2)(100-\mathrm{x})(\mathrm{Sb} 2 \mathrm{Se} 3)(\mathrm{x})$ glasses," Optical Materials Express, 4[3] 52540 (2014).

8. Liu, Q. M., Zhao, X. J., Tanaka, K., et al., "Second-harmonic generation in Ge-As-S glasses by electron beam irradiation and analysis of the poling mechanism," Opt. Commun., 198[1-3] $187-92(2001)$.

9. Harbold, J. M., Ilday, F. O., Wise, F. W., et al., "Highly nonlinear Ge-As-Se and Ge-As-S-Se glasses for all-optical switching," Ieee Photonics Technology Letters, 14[6] 822-24 (2002).

10. Lenz, G., Zimmermann, J., Katsufuji, T., et al., "Large Kerr effect in bulk Se-based chalcogenide glasses," Opt. Lett., 25[4] 254-56 (2000). 
11. Guignard, M., Nazabal, V., Smektala, F., et al., "Chalcogenide glasses based on germanium disulfide for second harmonic generation," Advanced Functional Materials, 17[16] 3284-94 (2007).

12. Caillaud, C., Gilles, C., Provino, L., et al., "Highly birefringent chalcogenide optical fiber for polarization-maintaining in the 3-8.5 mu m mid-IR window," Opt. Express, 24[8] 7977-86 (2016).

13. Caillaud, C., Renversez, G., Brilland, L., et al., "Photonic Bandgap Propagation in All-Solid Chalcogenide Microstructured Optical Fibers," Materials, 7[9] 6120-29 (2014).

14. Pagani, M., Vu, K., Choi, D. Y., et al., "Instantaneous microwave frequency measurement using four-wave mixing in a chalcogenide chip," Opt. Commun., 373 100-04 (2016).

15. Novak, S., Singh, V., Monmeyran, C., et al., "Positron annihilation lifetime spectroscopy (PALS) studies of gamma irradiated As2Se3 films used in MIR integrated photonics," Journal of NonCrystalline Solids, 455 29-34 (2017).

16. Gutierrez-Arroyo, A., Baudet, E., Bodiou, L., et al., "Optical characterization at $7.7 \mathrm{mu} \mathrm{m}$ of an integrated platform based on chalcogenide waveguides for sensing applications in the midinfrared," Opt. Express, 24[20] 23109-17 (2016).

17. Starecki, F., Charpentier, F., Doualan, J. L., et al., "Mid-IR optical sensor for CO2 detection based on fluorescence absorbance of Dy3+:Ga5Ge20Sb10S65 fibers," Sensors and Actuators BChemical, 207 518-25 (2015).

18. Michel, K., Bureau, B., Boussard-Pledel, C., et al., "Monitoring of pollutant in waste water by infrared spectroscopy using chalcogenide glass optical fibers," Sensors and Actuators BChemical, 101[1-2] 252-59 (2004).

19. Keirsse, J., Boussard-Pledel, C., Loreal, O., et al., "IR optical fiber sensor for biomedical applications," Vib. Spectrosc., 32[1] 23-32 (2003).

20. Eggleton, B. J., Luther-Davies, B., and Richardson, K., "Chalcogenide photonics," Nat. Photonics, 5[3] 141-48 (2011). 
21. Gai, X., Madden, S., Choi, D. Y., et al., "Dispersion engineered Ge11.5As24Se64.5 nanowires with a nonlinear parameter of 136W(-1)m(-1) at 1550nm," Opt. Express, 18[18] 18866-74 (2010).

22. Shportko, K., Kremers, S., Woda, M., et al., "Resonant bonding in crystalline phase-change materials," Nature Materials, 7[8] 653-58 (2008).

23. Chen, Y., Shen, X., Wang, R. P., et al., "Optical and structural properties of Ge-Sb-Se thin films fabricated by sputtering and thermal evaporation," J. Alloys Compd., 548 155-60 (2013).

24. Nazabal, V., Charpentier, F., Adam J-L., "Sputtering and Pulsed Laser Deposition for Near- and Mid-Infrared Applications: A Comparative Study of Ge25Sb10S65 and Ge25Sb10Se65 Amorphous Thin Films," International Journal of Applied Ceramic Technology, 8 990-1000 (2011).

25. Verger, F., Nazabal, V., Colas, F., et al., "RF sputtered amorphous chalcogenide thin films for surface enhanced infrared absorption spectroscopy," Opt. Mater. Express, 3[12] 2112-31 (2013).

26. Musgraves, J. D., Carlie, N., Hu, J., et al., "Comparison of the optical, thermal and structural properties of $\mathrm{Ge}-\mathrm{Sb}-\mathrm{S}$ thin films deposited using thermal evaporation and pulsed laser deposition techniques," Acta Mater., 59[12] 5032-39 (2011).

27. Nazabal, V., Cathelinaud, M., Shen, W., et al., "Chalcogenide coatings of Ge15Sb20S65 and Te20As30Se50," Appl. Optics, 47[13] C114-C23 (2008).

28. Charrier, J., M-L. Brandily, H. Lhermite, K. Michel, B. Bureau, F. Verger, V. Nazabal, "Evanescent wave optical micro-sensor based on chalcogenide glass," Sensors and Actuators B-Chemical, 173 468-76 (2012).

29. Ganjoo, A., Jain, H., Yu, C., et al., "Planar chalcogenide glass waveguides for IR evanescent wave sensors," Journal of Non-Crystalline Solids, 352[6-7] 584-88 (2006).

30. Haisty, R. W. and Krebs, H., "ELECTRICAL CONDUCTIVITY AND FORMATION OF CHALCOGENIDE GLASSES IN GE-AS-SE AND GE-SB-SE MELTS," Angew. Chem.-Int. Edit., 7[12] 947-48 (1968). 
31. Wei, W. H., Xiang, S., Xu, S. W., et al., "Structural investigation on GexSb10Se90-x glasses using x-ray photoelectron spectra," J. Appl. Phys., 115[18] 183506 (2014).

32. Ai, Z. P. and earth, R., "Luminescence of In $2 \mathrm{~S} 3$ nanocrystallites embedded in sol-gel silica xerogel," Optical Materials, 24[3] 589-93 (2003).

33. Baudet, E., Cardinaud, C., Girard, A., et al., "Structural analysis of RF sputtered Ge-Sb-Se thin films by Raman and X-ray photoelectron spectroscopies," J. Non-Cryst. Solids, 444 64-72 (2016).

34. Sati, D. C., Kovalskiy, A., Golovchak, R., et al., "Structure of SbxGe40-xSe60 glasses around 2.67 average coordination number," Journal of Non-Crystalline Solids, 358[2] 163-67 (2012).

35. Chen, Y., Xu, T. F., Shen, X., et al., "Optical and structure properties of amorphous Ge-Sb-Se films for ultrafast all-optical signal processing," J. Alloy. Compd., 580 578-83 (2013).

36. Pethes, I., Chahal, R., Nazabal, V., et al., "Chemical Short-Range Order in Selenide and Telluride Glasses," J. Phys. Chem. B, 120[34] 9204-14 (2016).

37. McGreevy, R. L. and Pusztai, L., "REVERSE MONTE CARLO SIMULATION: A NEW TECHNIQUE FOR THE DETERMINATION OF DISORDERED STRUCTURES," Mol. Simul., 1[6] 359-67 (1988). 


\section{Figure captions}

Fig 1. Survey XPS spectrum of $\mathrm{Ge}_{23.5} \mathrm{Sb}_{11.8} \mathrm{Se}_{64.7}(\mathrm{x}=20)$ as-deposited thin film.

Fig. 2. Comparison of chemical composition of $\left(\mathrm{GeSe}_{2}\right)_{100-\mathrm{x}}\left(\mathrm{Sb}_{2} \mathrm{Se}_{3}\right)_{\mathrm{x}}$ PLD films determined by $\operatorname{EDS}( \pm 1 \%)$ and XPS $( \pm 1 \%)$ analysis compared to theoretical composition.

Fig. 3. XPS spectra of as-deposited $\left(\mathrm{GeSe}_{2}\right)_{100-\mathrm{x}}\left(\mathrm{Sb}_{2} \mathrm{Se}_{3}\right)_{\mathrm{x}} \mathrm{PLD}$ thin films. Data fitting of Ge 3d and Sb 4d core level bands: a) $x=5$, b) $x=20$ and c) $x=60$; data fitting of Se $3 d$ core level bands: d) $x=5$, e) $x=20$ and f) $x=60$. Being very weak, the $\mathrm{Se}_{\mathrm{y}}-\mathrm{Ge}-\mathrm{O}_{\mathrm{x}}$ components are not shown in the curves fitting.

Fig. 4. Normalized core level band of $\mathrm{Ge} 3 \mathrm{~d}-\mathrm{Sb} 4 \mathrm{~d}$ (a) and $\mathrm{Se} 3 \mathrm{~d}(\mathrm{~b})$ of $\left(\mathrm{GeSe}_{2}\right)_{100-}$ ${ }_{x}\left(\mathrm{Sb}_{2} \mathrm{Se}_{3}\right)_{\mathrm{x}}$ PLD thin films. Dashed lines correspond to the binding energy (BE, eV) of the sample used for the calibration $(\mathrm{x}=10)$.

Fig. 5. $\mathrm{M}-\mathrm{M}$ bonds $(\mathrm{M}=\mathrm{Ge}, \mathrm{Sb})$ proportions (at. \%, $\pm 1 \%$ ) in $\mathrm{Ge} 3 \mathrm{~d}$ and $\mathrm{Sb} 4 \mathrm{~d}$ core level spectra depending of $\mathrm{x}$ values in $\left(\mathrm{GeSe}_{2}\right)_{100-\mathrm{x}}\left(\mathrm{Sb}_{2} \mathrm{Se}_{3}\right)_{\mathrm{x}}$ PLD thin films (dashed curve corresponds to the overall trend of M-M bonds as a function of $\mathrm{x}$ values). 


\section{Tables}

Table I. Theoretical and real chemical composition (at. \%) determined by EDS for chalcogenide glass targets $\left(\mathrm{GeSe}_{2}\right)_{100-\mathrm{x}}\left(\mathrm{Sb}_{2} \mathrm{Se}_{3}\right)_{\mathrm{x}}( \pm 0.5 \%)$ and corresponding thin films prepared by pulsed laser deposition $( \pm 1 \%)$.

\begin{tabular}{l|ccc|ccc|ccc}
\hline & \multicolumn{2}{|c|}{ Theoretical composition } & \multicolumn{2}{|c|}{ Target composition } & \multicolumn{2}{|c}{ Thin film composition } \\
\hline & \%Ge & \%Sb & \%Se & \%Ge & \%Sb & \%Se & \%Ge & \%Sb & \%Se \\
\hline $\mathbf{x = 0}$ & 33.3 & - & 66.7 & 36.5 & - & 63.5 & 39 & - & 61 \\
$\mathbf{x = 5}$ & 30.6 & 3.2 & 66.1 & 31.0 & 3.4 & 65.6 & 33 & 4 & 63 \\
$\mathbf{x = 1 0}$ & 28.1 & 6.3 & 65.6 & 28.3 & 6.8 & 64.9 & 30 & 8 & 62 \\
$\mathbf{x = 2 0}$ & 23.5 & 11.8 & 64.7 & 23.1 & 13.0 & 63.9 & 24 & 15 & 61 \\
$\mathbf{x = 3 0}$ & 19.4 & 16.7 & 63.9 & 19.5 & 17.8 & 62.7 & 19 & 21 & 60 \\
$\mathbf{x = 4 0}$ & 15.8 & 21.1 & 63.2 & 14.9 & 22.3 & 62.8 & 15 & 26 & 59 \\
$\mathbf{x = 5 0}$ & 12.5 & 25.0 & 62.5 & 12.1 & 25.4 & 62.5 & 13 & 27 & 61 \\
$\mathbf{x = 6 0}$ & 9.5 & 28.6 & 61.9 & 10.4 & 29.1 & 60.5 & 9 & 29 & 62 \\
\hline
\end{tabular}


Table II. Binding energy (BE, eV, $\pm 0.05 \mathrm{eV})$, full width at half maximum (FWHM, eV, $\pm 0.05 \mathrm{eV})$, proportion of bonds $(\%$ bonds, $\pm 1 \%)$ and atomic ratio $\left(\%\right.$ at, $\pm 1 \%$ ) of the different components used for the fitting of Se $3 \mathrm{~d}_{5 / 2}$, Ge $3 \mathrm{~d}_{5 / 2}, \mathrm{Sb} 4 \mathrm{~d}_{5 / 2}$ and Sb $3 \mathrm{~d}_{5 / 2}$ core level spectra of as-deposited $\left(\mathrm{GeSe}_{2}\right)_{100-\mathrm{x}}\left(\mathrm{Sb}_{2} \mathrm{Se}_{3}\right)_{\mathrm{x}}$ thin films prepared by pulsed laser deposition.

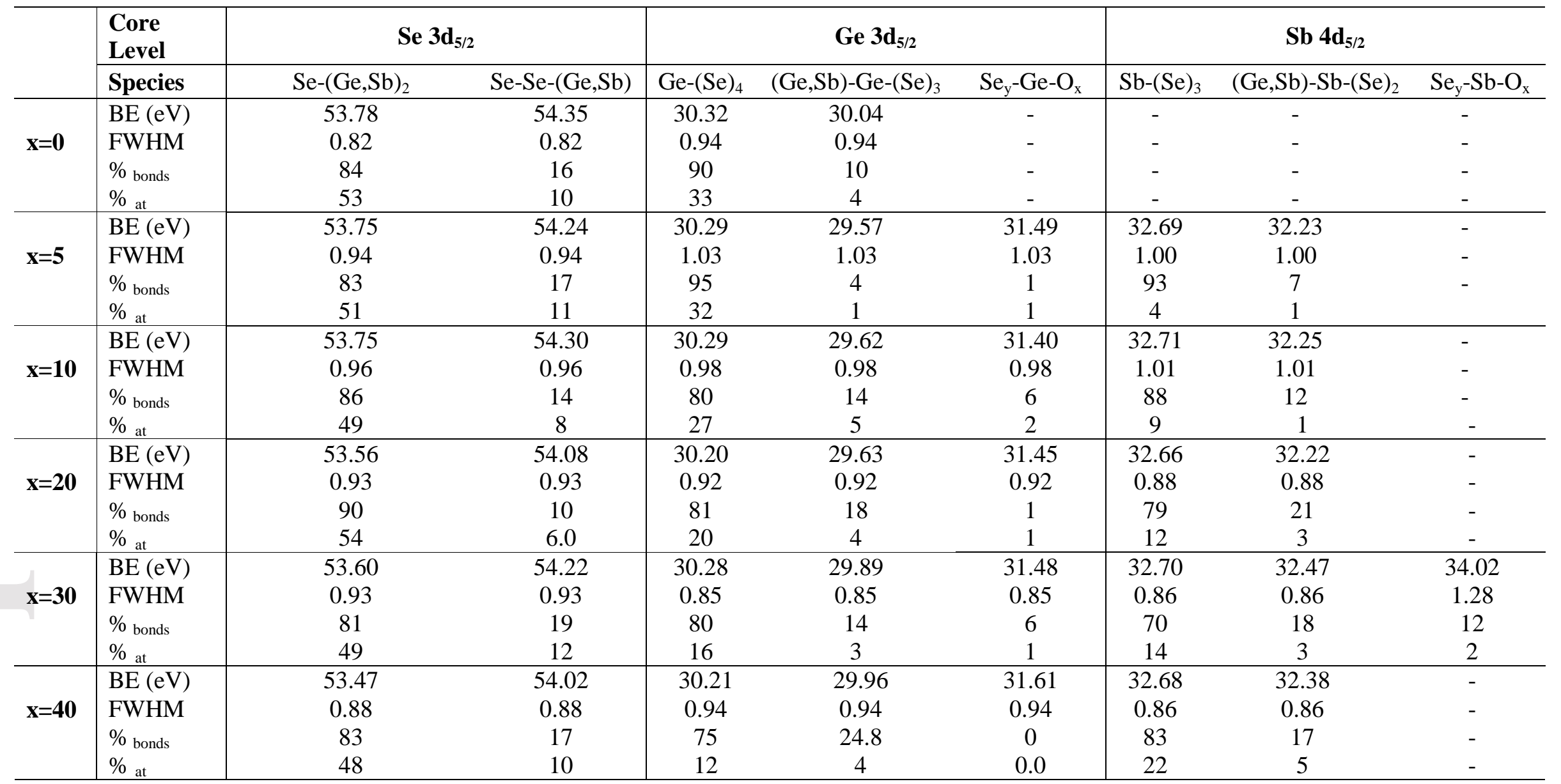




\begin{tabular}{l|l|cc|ccc|ccc}
\hline \multirow{3}{*}{$\mathbf{x = 5 0}$} & BE $(\mathrm{eV})$ & 53.56 & 54.06 & 30.32 & 29.85 & 31.61 & 32.78 & 32.41 \\
& FWHM & 0.82 & 0.82 & 0.75 & 0.75 & 0.75 & 0.87 & 0.87 & - \\
& $\%_{\text {bonds }}$ & 84 & 16 & 60 & 29 & 11 & 85 & - \\
& $\%_{\text {at }}$ & 47 & 9 & 7 & 4 & 1 & 27 & 5 \\
\hline \multirow{3}{*}{$\mathbf{x = 6 0}$} & BE $(\mathrm{eV})$ & 53.58 & 54.15 & 30.35 & 29.99 & 31.64 & 32.78 & 32.65 \\
& FWHM & 0.84 & 0.84 & 0.82 & 0.82 & 0.82 & 0.84 & 0.84 & - \\
& $\%_{\text {bonds }}$ & 83 & 17 & 79 & 17 & 5 & 92 & 8 & - \\
& $\%_{\text {at }}$ & 49 & 10 & 8 & 2 & 1 & 28 & - \\
\hline
\end{tabular}



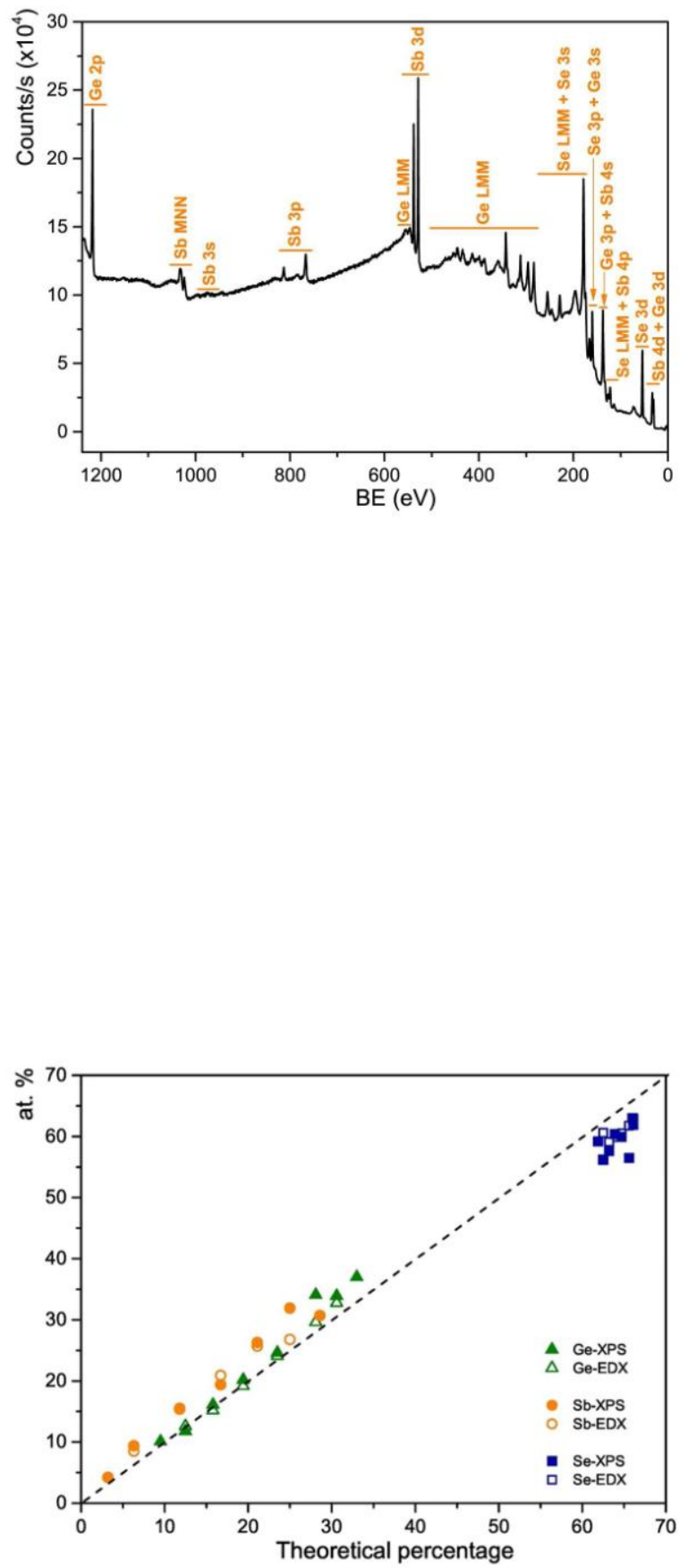

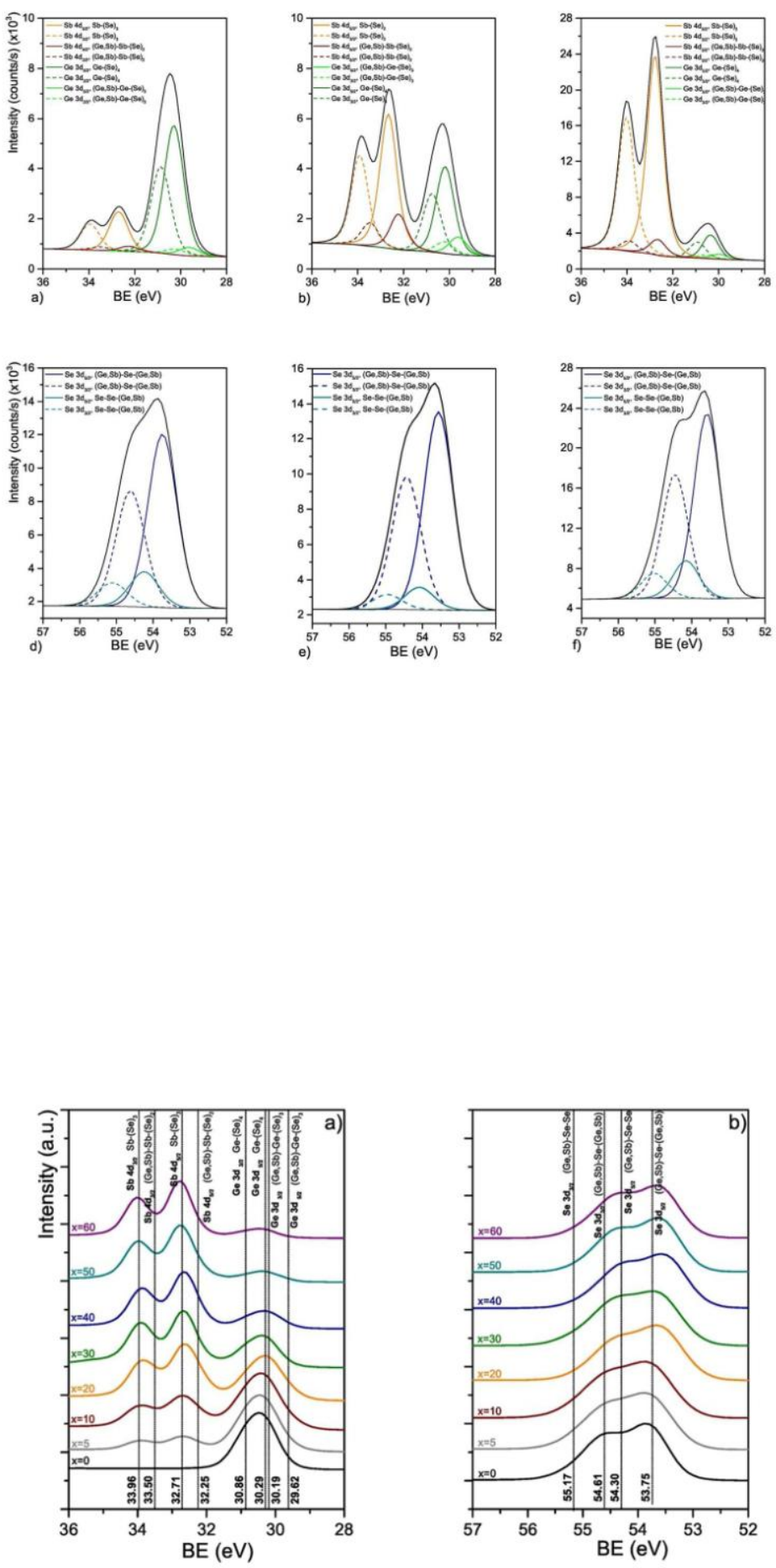


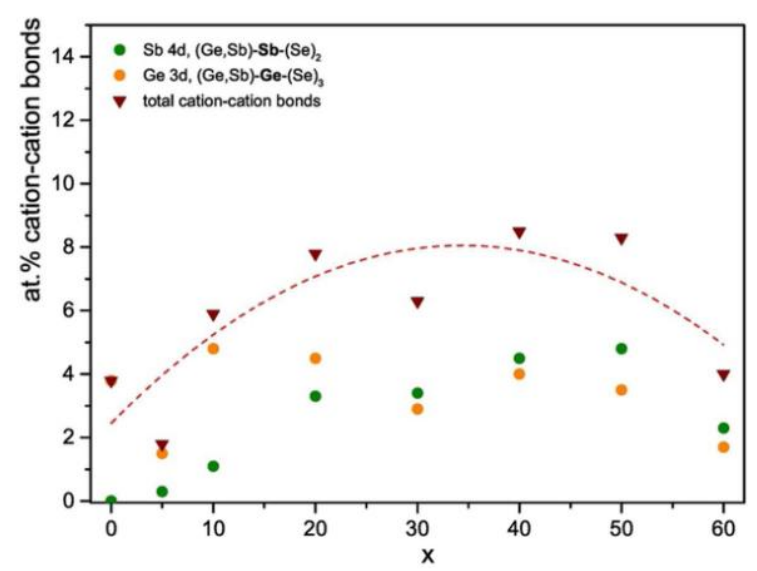

